\title{
The practical application of the course " debate competition " in the education and teaching of the Introduction on the Basic Principles of Marxism
}

\author{
Leifeng Wang ${ }^{1, a}$ \\ 1Jingdezhen Ceramics Institute, Jingdezhen, jiangxi, China \\ awangleifeng@163.com
}

Keywords: the course " debate competition " ; the Introduction on the Basic Principles of Marxism; the practical application

\begin{abstract}
Absrtact: First of all, this paper analyzes what is the "introduction of basic Principles of Marxism" course " debate competition ", and then explains why the curriculum debate competition into the "Basic principles of Marxism" education and teaching, and finally explore the curriculum debate competition into the "Basic principles of Marxism" education and teaching.
\end{abstract}

\section{课程 “辩论赛” 在《马克思主义基本原理概论》 教育教学中的实践应用研究}

\author{
王否峰, ${ }^{1}$ \\ 1 景德镇陶瓷大学,江西省景德镇市 \\ awangleifeng@163.com,b85474966@qq.com
}

关键词: 课程辩论赛; 马克思主义基本原理概论; 实践应用;

摘要：本论文首先分析何谓《马克思主义基本原理概论》课程“辩论赛”，其次阐述为什么将 课程辩论赛融入《马克思主义基本原理概论》教育与教学中, 最后探析将课程辩论赛融入《马 克思主义基本原理概论》教育与教学中。

\section{1. 引言}

本文从《马克思主义基本原理概论》课程出发, 研究课程“辩论赛”在《马克思主义基本原 理概论》教育教学中的实践应用有着重要理论意义与实践价值。为此, 要弄清楚什么是《马 克思主义基本原理概论》课程“辩论赛”, 为什么以及怎样将课程辩论赛融入《马克思主义基 本原理概论》教育与教学中等三个问题, 以便增强大学生对《马克思主义基本原理概论》课程 “辩论赛”的兴趣, 提高其分析问题与解决问题的能力。有利于克服由原理的抽象性带来的枯 燥甚至空洞, 不断提升新时代高校思想政治理论课的亲和力和针对性, 不断增加大学生的获 得感、幸福感。

\section{2. 何谓《马克思主义基本原理概论》课程“辩论赛”}

辩论, 指双方利用一定哲学原理来说明自己对某一问题的见解, 在相互揭露对方的矛盾 中最终达成一定的认识或共同的观点。辩论赛是参赛双方就某一问题或观点进行辩论的一种 知识竞赛活动, 通常是看谁概念界定更准确, 逻辑更严谨, 表达更生动, 价值更高等等, 说 服对象不是对方, 而是台下的观众和评委。而《马克思主义基本原理概论课》“辩论赛”是以 
《马克思主义基本原理概论课》为中心, 设置一定的具有哲理的选题, 让大学生围绕选题而 展开的一种思维反映能力的竞赛, 一种语言表达能力的竞赛, 是一种综合能力的竞赛, 更是 一种哲理知识运用的竞赛。 ${ }^{[1]}$ 目的在于让同学们将马克思主义基本原理运用到实践生活中, 并让同学们对马克思主义基本原理有更加深刻的认识。一场辩论赛的成功, 不仅是个人风采 的体现, 更重要的是一种团队精神, 是群策群力。比赛中较量的, 不仅仅是知识, 智慧, 更 在于我们如何做人，如何与他人很好的合作。《马克思主义基本原理概论课》“辩论赛”的作用 在于增强大学生明辨是非能力、逻辑思维能力和语言表达能力, 探察世道治乱的标准, 判断 事物同异的根据, 权衡利弊得失, 解决大学生思想上存在的疑惑。在辩论的过程中, 同学们 所要具备的哲理知识与能力是多方面的, 为了这个目的, 他们在台上充分展示自己, 能力也 在不知不觉中提高。首先, 思维能力得到提高。如果没有对事物的真知灼见, 就不会有惊人 妙语。如果没有如泉思绪, 就不可能口若悬河。思维的深刻性、论证性和敏捷性都得到了提 高。同时同学们在赛前准备时看问题更深刻了, 不再停留在很肤浅的表面, 也学会了多角度 思考问题。其次, 同学们语言表达更具艺术性。经过几场锻炼, 每个选手在语速与语调的协 调上把握都很好，甚至形成了自己的风格，同时对汉语言的使用能力增强。

\section{3. 为什么将课程辩论赛融入 《马克思主义基本原理概论》教育与教学中}

根据“19大”报告、《新时代高校思想政治理论课教学工作基本要求》、《国家中长期教育改 革和发展规划纲要 (2010-2020)》“深化教育教学改革, 创新教育教学方法”的精神, 把课程“辩 论赛”运用到《马克思主义基本原理概论》教育教学中, 有利于习近平新时代中国特色社会主 义思想进教材进课堂进学生头脑, 有助于创新《马克思主义基本原理概论》课程实践教育教 学模式。有利于克服由理论的抽象性带来的枯燥甚至空洞, 使大学生的思维水平、表达能力、 写作水平与创作能力得到显著提升。具体有以下三点原因: 第一, 是贯彻党的教育方针, 增 强新时代高校思想政治理论课时代感和吸引力的需要。包括贯彻党的教育方针的需要、增强 新时代高校思想政治理论课时代感和吸引力的需要; 第二, 是高校对大学生进行思想政治教 育的主阵地, 是创新《马克思主义基本原理概论》课程实践教育教学模式的需要。包括对大 学生进行有效的思想政治教育, 创新《马克思主义基本原理概论》课程实践教育教学模式; 第三, 是提升大学生对马克思主义基本原理认同, 帮助大学生从辩论中成长且综合素质与能 力全面发展的需要。包括提升大学生对马克思主义基本原理的理论认同、情感认同与行为认 同, 大学生从辩论中成长且综合素质与能力全面发展。

\section{4. 怎样将课程辩论赛融入 《马克思主义基本原理概论》教育与教学中}

实施课程辩论是一个系统的工程, 苏联教育家苏霍姆林斯基认为, 课堂中的一切困惑和 失败绝大多数在于教师忘却了上课是教师和学生的共同活动。 ${ }^{[2]}$ 因此, 《马克思主义基本原 理概论》课程“辩论赛” 从选题的拟定、比赛过程及其结果总结等需要学生与教师共同精心组 织。通过近几年的尝试, 认为根据实施效果的情况应该在如下方面推广课程辩论赛: 1. 辩论 赛主题来源。可由任课教师指定内容交由学生进行主题编写, 也可由学生自由创作, 拟定 2-5 场辩论赛主题。但是注意提醒学生尽可能选择具有哲学意义的题目, 并能够灵活运用、体现 唯物辩证法即及其矛盾规律等。2. 组对方式。第一, 根据课堂人数多少, 分成小组; 第二, 正方、反方人数不限，但正方、反方须确定两名同学各自担任“一辩手”和“四辩手”的任务。 3. 辩论赛程序。第一步, 由正方一辩手阐述正方的观点, 然后有反方一辩手发言; 第二步, 自由辩论, 正方、反方轮流发言; 第三步, 先有反方四辩手作结案陈词, 再有正方四辩手发 言总结。4. 服务工作。为了更好地锻炼学生各方面的能力, 组织服务工作都由学生班级承担 服务。小组成员由班的学生干部组成（也可以是普通同学）。比赛评委由表演双方班级共同 从班级中推荐产生, 一组一个, 评委原则上最少由 3 人组成, 任课教师一般应作为评委。点 
评人自荐, 并点评本场辩论赛。评委评分细则另行规定。5. 表彰。在比赛表演过程中表现突 出的学生给予平时成绩鼓励政策, 原则上在现有平时表现基础上浮, 直至平时成绩最高（30 分）。

综上, 通过《马克思主义基本原理概论》课程“辩论赛”, 将抽象的理论还原到具体的实 践当中, 使学生感受到唯物辩证法的理论魅力, 并将其自觉应用到认识问题、解决实际问题 当中去。一方面, 创新该课程的学习方式, 并对成果固化提升, 从而增强学习效果; 另一方 面, 使大学生在教育教学中感受到马克思主义基本原理的重要性, 与自己生活、学习乃至将 来的工作都有重大关联, 从而真学、真懂、真用马克思主义基本立场、基本观点与基本方法, 在“德智体美”方面获得全面发展，成为培养担当民族复兴大任的时代新人。

\section{5. 致谢}

本文为教育部高校示范马克思主义学院和优秀教学团队建设项目“一课一品, 重在践 行”一—思想政治理论课实践教学改革的实施(17JDSZK030); 2016 年景德镇陶瓷大学校级教 改项目“马克思主义人学思想视角下的“以生为本”研究一以江西省部分高校为例”(212050-007) 的阶段性成果; 本文为 2016 年景德镇陶瓷大学研究生课题项目“当代研究生社会主义核心价 值观培育研究”(213040-00101)的阶段性成果。

\section{References}

[1] Yang Guobin, Shang Ming Li. The thought on the "Basic principles of Marxism" to carry out the course debate competition [J]. Journal of North China Water Conservancy and hydropower University (social Science Edition), 2017 (6).

[2] Zeng Yihong. Design and application of thematic participation in interactive teaching scheme [J]. Journal of ideological and Theoretical education, 2010 (5) 